\title{
Commentary: The mutation matters: Improving precision for surgical management of hereditary aortic syndromes
}

\author{
Holly N. Smith, MD, MBA, and \\ Paul W. M. Fedak, MD, PhD, FRCS(C)
}

Hereditary aortic diseases can present challenging surgical management decisions for clinicians. To date, clinical expert guidelines have lacked precision. Guidelines often fail to consider important pathophysiological differences between different inherited thoracic aortic diseases and how underlying cellular and molecular mechanisms can influence surgical outcomes. ${ }^{1}$ The exponential growth of computing power combined with the evolution of high resolution, multimodal advanced imaging technologies offers the promise of more precise diagnostic and predictive tools to assess disease progression and in so doing, influence surgical approaches. With further advances in molecular biology, we gain an increased understanding of disease pathogenesis at the level of the gene, protein, and cell. We now have an opportunity to achieve personalized treatment strategies for the surgical management of thoracic aortic disease.

Bicuspid aortic valve-associated aortopathy, once considered a milder version of Marfan syndrome (MFS), is increasingly understood as triggered by hemodynamic aberrations. Clinical expert recommendations for prophylactic aortic resection in bicuspid-associated aortopathy have become more conservative over time, recognizing this less-aggressive disease pathway compared with genetic connective tissue diseases. ${ }^{2}$ Emerging methods will validate and improve patient risk stratification such as 4-dimensional-flow magnetic resonance imaging

\footnotetext{
From the Section of Cardiac Surgery, Department of Cardiac Sciences, Cumming School of Medicine, University of Calgary, Libin Cardiovascular Institute, Calgary, Alberta, Canada.

Disclosures: The authors reported no conflicts of interest.

The Journal policy requires editors and reviewers to disclose conflicts of interest and to decline handling or reviewing manuscripts for which they may have a conflict of interest. The editors and reviewers of this article have no conflicts of interest.

Received for publication Aug 23, 2020; revisions received Aug 23, 2020; accepted for publication Aug 24, 2020; available ahead of print Aug 28, 2020.

Address for reprints: Paul W. M. Fedak, MD, PhD, FRCS(C), Section of Cardiac Surgery, Department of Cardiac Sciences, Cumming School of Medicine, University of Calgary, Libin Cardiovascular Institute, C849, 1403-29th St, NW, Calgary, Alberta, T2N 2T9 Canada (E-mail: paul.fedak@gmail.com).

J Thorac Cardiovasc Surg 2022;164:29-30

$0022-5223 / \$ 36.00$

Copyright (c) 2020 by The American Association for Thoracic Surgery

https://doi.org/10.1016/j.jtcvs.2020.08.077
}

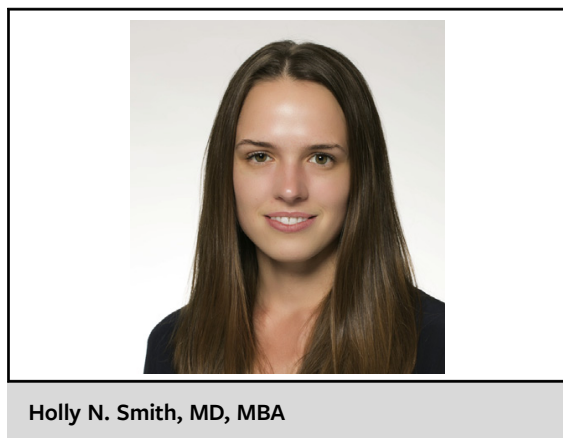

\begin{abstract}
CENTRAL MESSAGE
An improved understanding of hereditary aortic syndromes reveals a need for more precise and individualized surgical treatment approaches.
\end{abstract}

measures of flow-mediated wall shear stress and novel circulating biomarkers. $^{3,4}$

Loeys-Dietz Syndrome (LDS), previously classified as a subset of MFS, is recognized as a unique clinical condition. However, contemporary medical and surgical treatment recommendations for LDS are similar to those made for MFS. ${ }^{5,6}$ Sieke and colleagues ${ }^{7}$ develop more precise surgical management strategies for people with LDS and MFS. ${ }^{7}$ Following an index surgical procedure, the study results show a significantly higher incidence of reoperation and dissection in LDS patients compared with MFS patients. Specifically, the need for aortic arch reoperations is substantially increased with LDS. The investigators appropriately suggest that more aggressive surgical resection is warranted in LDS patients. We should give greater consideration to prophylactic aortic arch intervention at the time of initial operation. The lower incidence of reoperation in MFS suggests that a comparatively conservative surgical approach, particularly without associated aortic dissection, is prudent.

Current management strategies for prophylactic aortic resection employ aortic diameter measures to predict the future risk of acute aortic catastrophe. Aortic diameter as a predictive tool has significant inherent limitations. ${ }^{8}$ Aortic size alone may be particularly imprecise for gene mutations of connective tissue regulation, like MFS and LDS because aortic tissue biomechanics and vascular wall tensile strength may be highly abnormal at smaller diameters. Alternate measures of biomechanical properties may improve prediction of acute aortic events. ${ }^{1,9}$ 
The mutation matters. Advanced imaging modalities and concomitant use of circulating biomarkers may improve our ability to predict an individual's risk of future aortic events. Improving precision in our decisions for prophylactic aortic resection is an excellent opportunity for surgeons interested in collaborative, multidisciplinary research. Rigorous clinical follow-up with formal reporting of surgical outcomes for all cases of hereditary aortic diseases, as achieved by Sieke and colleagues, ${ }^{7}$ should be implemented by all surgical programs of excellence.

\section{References}

1. Fletcher AJ, Syed MBJ, Aiman TJ, Newby DE, Walker NL. Inherited thoracic aortic disease: new insights and translational targets. Circulation. 2020;141: 1570-87.

2. Borger MA, Fedak PWM, Stephens EH, Gleason TG, Girdauskas E, Ikonomidis JS, et al. The American Association for Thoracic Surgery consensus guidelines on bicuspid aortic valve-related aortopathy: executive summary. $J$ Thorac Cardiovasc Surg. 2018;156:473-80.

3. Maredia AK, Greenway SC, Verma S, Fedak PWM. Bicuspid aortic valveassociated aortopathy: update on biomarkers. Curr Opin Cardiol. 2018;33:134-9.

4. Bollache E, Guzzardi DG, Sattari S, Olsen KE, Di Martina ES, Malaisrie SC, et al. Aortic valve-mediated wall shear stress is heterogeneous and predicts regional aortic elastic fiber thinning in bicuspid aortic valve-associated aortopathy. $J$ Thorac Cardiovasc Surg. 2018;156:2112-20.
5. Hiratzka LF, Bakris GL, Beckman JA, Bersin RM, Carr VF, Casey DE Jr, et al American College of Cardiology Foundation/American Heart Association Task Force on Practice Guidelines, American Association for Thoracic Surgery, American College of Radiology, American Stroke Association, Society of Cardiovascular Anesthesiologists, Society for Cardiovascular Angiography and Interventions, Society of Interventional Radiology, Society of Thoracic Surgeons, Society for Vascular Medicine. 2010 ACCF/AHA/AATS/ACR/ASA/SCA/SCAI/SIR/STS/ SVM guidelines for the diagnosis and management of patients with thoracic aortic disease: a report of the American College of Cardiology Foundation/American Heart Association task force on practice guidelines, American Association for Thoracic Surgery, American College of Radiology, American Stroke Association, Society of Cardiovascular Anesthesiologists, Society for Cardiovascular Angiography and Interventions, Society of Interventional Radiology, Society of Thoracic Surgeons, and Society for Vascular Medicine. Circulation. 2010;121:e266-369.

6. Erbel R, Aboyans V, Boileau C, Bossone E, Bartolomeo RD, Eggebrecht H, et al; ESC Committee for Practice Guidelines. 2014 ESC guidelines on the diagnosis and treatment of aortic diseases: document covering acute and chronic aortic diseases of the thoracic and abdominal aorta of the adult: the task force for the diagnosis and treatment of aortic diseases of the European Society of Cardiology (ESC). Eur Heart J. 2014;35:2873-926.

7. Seike Y, Matsuda H, Inoue Y, Sasaki H, Morisaki H, Morisaki T, et al. The differences in surgical long-term outcomes between Marfan syndrome and Loeys-Dietz syndrome. J Thorac Cardiovasc Surg. 2022;164:16-25.e2.

8. Pape LA, Tsai TT, Isselbacher EM, Oh JK, O'gara PT, Evangelista A, et al. Aortic diameter $\geq 5.5 \mathrm{~cm}$ is not a good predictor of type A aortic dissection: observations from the international registry of acute aortic dissection (IRAD). Circulation. 2007; 116:1120-7.

9. Gregory AJ, Di Martino E, Fedak PWM. Aortic diameter: the beginning of the end of an era. J Thorac Cardiovasc Surg. 2018;156:513-4. 